\title{
Hierarchical Production of Privacy: Gating in Compact Living in Hong Kong
}

\author{
Jun Wang ${ }^{1}$, Stephen S. Y. Lau \\ ${ }^{1}$ Department of Public Policy, City University of Hong Kong, Hong Kong, China \\ ${ }^{2}$ Department of Architecture, University of Hong Kong, Hong Kong, China \\ Email: june.wang@cityu.edu.hk
}

Received April 28 ${ }^{\text {th }}$, 2013; revised May 31 ${ }^{\text {st }}, 2013$; accepted June $7^{\text {th }}$, 2013

\begin{abstract}
Copyright (C 2013 Jun Wang, Stephen S. Y. Lau. This is an open access article distributed under the Creative Commons Attribution License, which permits unrestricted use, distribution, and reproduction in any medium, provided the original work is properly cited.
\end{abstract}

\begin{abstract}
Measured by both the physically fortified character and socio-legal systems of service delivery and governance, the number of neighborhoods in Hong Kong that falls into the category of gated community is huge. Gating here is widely employed in various types of housing estates, from luxury developments for the affluent, to aged tenement houses that usually house the less advantaged group, and even to public housing for the population segment who are at the very bottom of the social strata. In the densely populated Hong Kong, privacy is a rare urban resource, the competition for which thus leads to valorization of buffer between public and private lives in a hierarchical way. Gating, in its various forms and correspondingly varying magnificence to which one's privacy is protected and separated from the public, then serves as the marker of social differences. This paper attempts to investigate the hierarchy in three tiers, with a focus on Tier Three, where vertical gating is invented as another dimension to mark social differences in the composite development model.
\end{abstract}

Keywords: Gated Community; Privacy; Hierarchical Production

\section{Introduction: The Debate on Gated Community and the Widely Application in Hong Kong}

The definition of gated community itself has been contested. Generally speaking, gated community refers to residential development "that restrict public access, usually through the use of gates, booms, walls and fences", or may "through employ[ing] security staff or CCTV system to monitor access" (Atkinson \& Blandy, 2005). Besides these visible physical features, the socio-legal framework behind such community is also argued to be a central characteristic. It is under the legal system that "residents subscribe to access and occupation of these developments, in combination with the physical features which make them so conspicuous" (Atkinson \& Blandy, 2005). The proliferation of gated community evoked considerable concerns in the West (Webster, Glasze, \& Frantz, 2002; Mitchell, 1995), where scholars worry that such a fortified style of development will lead to an end of public space (Mitchell, 1995), may cause unexpected social consequences like social exclusion and thus social segregation and polarization (Manzi \& Smith-Bowers, 2005).

Measured by these two dimensions concurrently, namely, physically fortified character and socio-legal systems of service delivery and governance, the number of neighborhoods in Hong Kong that falls into the category of gated community is huge. Like many other Chinese cities, gating is nothing new in Hong Kong. Court-yard house (Siheyuan) and the traditional Chinese model of city are all walled entities (Huang, 2006; Knapp, 1999, 2000). Although there is no Work Unit compound in the capitalistic city of Hong Kong, the morphology of gating sustains and soon appears in Hong Kong's high-rise residential buildings with a modernized outlook. Nowadays, gating is widely employed in various types of housing estates, from luxury developments for the affluent, to aged tenement houses that usually house the less advantaged group, and even to public housing for the population segment at the very bottom of the social strata (Li \& Siu, 2001). Nevertheless, different from the worries and concerns commonly expressed in the West, the locals generally hold a positive attitude to gating. Physical gating in Hong Kong, no matter in forms of wall, fence or high-tech CCTV system, is frequently taken as an inherent element for a residential development, and naturally a must-have item in any form of housing evaluation. In a survey we conducted, hardly no resident hide his/her appreciation of living in a gated or protected residence.

Whilst gating is common in the residential culture of Chinese, gating in Hong Kong bears unique characteristics in response to its urban context, which is well known for a high density and high-rise model. This paper argues that understanding of gating in Hong Kong may only be achieved when it is put into the broader geographic, historical and socio-cultural circumstances that the city has gone through.

\section{Review of Literature on the Debates}

Among the debates on gated communities, there are two main explanations for the cause of gated community. One is the fear theory which sees fortification of urban residential space as a result of the fear of crime (Atkinson et al., 2004), and the desire for privacy "through the pursuit of security" (Atkinson \& 
Blandy, 2005). Another explanation is the club realm theory (Webster, 2001), which sees gate community as an efficient way of service providing. In a city where the municipal government fails to offer stratified services, gated community then takes this responsibility through organized household committees and/or professional property management agents to design and offer services at a price that corresponds to the consumption power of the residents.

This paper attempts to explore from the production side, that is, the competition for urban resources in the process of space production. In his book of "Distinction: a social critique of the judgment of taste”, Bourdieu (1984) points out that,

"the consumption of the most legitimate cultural goods is a particular case of competition for rare goods and practices, whose particularity no doubt owes more to the logic of supply, i.e., the specific form of competition between the producers, than to the logic of demand and tastes, i.e., the logic of competition between consumers (Bourdieu, 1984)...

the abstract relationship between consumers with interchangeable tastes and products with uniformly perceived and appreciated properties to the relationship between tastes which vary in a necessary way according to their social and economic conditions of production, and the products on which they confer their different social identities (Bourdieu, 1984)".

In Hong Kong where gating is commonly applied to almost all kinds of residential developments, it is hard to claim that gated community may represent special lifestyle, or special needs by a homogeneous social group with shared value. Hong Kong is a special case of its own, its specialness is a product of an extremity of overcrowding, ever-increasing growth in population, and a scarcity of land resource.

In the compact city of Hong Kong, residents are squeezed into a dense pattern and as a result, privacy is always under threat. Although Chinese culture is more adaptable to low privacy levels (Chan, 1999), but the desire for privacy which stems from the Western individualistic society is also seen penetrating into the Hong Kong traditionally collectivist culture. The notion of privacy in the Hong Kong scenario stems as a reaction to the extreme density. In his research on the social impact of high density living in Hong Kong, Mitchell (1971) shows that lack of privacy is clearly related to the magnificent of density. According to Lansing (cited by Alexander, Reed, \& Murphy 1988), people in Hong Kong are aware of and respond to a perceived lack of space. Also, complaints such as lack of space and lack of privacy arise in response to high densities.

The buffer between private and public lives thus become a rare urban resource. As for housing production and consumption, one thing that attracted common attention is the level at which and the extent to which a given community is separated from the public. At the same time, this lack of distance, or an ill definition of territorial space is, for most cases, a common way of life that exists almost as old as the city itself (Lau \& Wang, 2002). Given the situation of Hong Kong, zones like the Peak, the waterfront of the Stanley Peninsula or the Repulse Bay, which are affordable only by the limited group at the very top of the social strata, naturally afford a relatively easily recognizable buffer between the private and public, and thus develop that kind of a concept of "self", "us" and private life. For the remaining parts of the city, however, other proxies other than the physical distance afforded by natural settings must be invented to serve as buffer. Gating, in this light, appears as an important niche for marketing strategy, taking on varying forms, from a wall surrounding a cluster of buildings, an elevated platform above the street, to a door with a restricted access by means of an access code. What matters is not only the form of gating, but more in terms of the indication of social differentiation. It is interesting to explore how a hierarchy of production of "privacy" is gradually established through gating in Hong Kong. Gating, in its various forms and correspondingly varying magnificence to which one's privacy is protected and separated from the public, then serves as a marker of social differences.

\section{Understanding Gating in a Compact Setting High-Density and High-Rise Development}

The story of Hong Kong as a Sky City distinguishes the city by mainly two elements, dramatic population density at the horizontal level and staggering heights of buildings at the vertical level (see Table 1). Hong Kong has continuous problems of land scarcity and increasing population, both of which have eventually led to a world record high compactness. Although the territory of Hong Kong covers an area of 1098 sq.km, yet only $21.1 \%$ of its total land area is built-up set off great pressure on accommodating its population. The situation is made even more serious by the continuous influx of immigrants, most of who migrated in a rush to the city from mainland China since the early 1960s. The post-1997 era saw a daily increase of 150 numbers of legal immigrants. This small figure is actually a significant attribute to the population increase that generated an additional one million population per decade over the past decades (Lau \& Wang, 2002).

As a result, over $50 \%$ of Hong Kong's 6.7 million populations (mid-2001 figure) live and work in urban centers (Lau \& Wang, 2002), namely, the narrow strip of land along the Victoria Harbor on Hong Kong Island and the Kowloon Peninsula. Hong Kong today has an average density of 6310-person per square kilometer and a peak urban density of 44,210 people per square kilometer (Lau \& Wang, 2002)-Mongkok and Kwun Tong are two localities which exhibit extreme density that is among the top in the world (see Figure 1).

Density in Hong Kong is easily detectable through the mini size of street blocks. The shortage of land and the incessant needs for housing pushed up the land price drastically, and in turn most developers can only afford small pieces. Land in the urban centers was divided into small fragments. These land parcels are often, too tight a space to allow any recessions, as a result, buildings erected on them frequently cover the entire site. In such a compact city, developers, as well as the government, soon realized the importance to develop towards the vertical dimension.

Table 1.

Comparison of population density of different cities in 2001.

\begin{tabular}{cccc}
\hline Cities & Hong Kong & London & Tokyo \\
\hline $\begin{array}{c}\text { Land area (sq.km) } \\
\begin{array}{c}\text { Population density } \\
\text { (persons per sq.km) }\end{array}\end{array}$ & 1075 & 1578 & 2187 \\
\hline
\end{tabular}

(Sources complied from: United Nation Annual Report, 2001). 


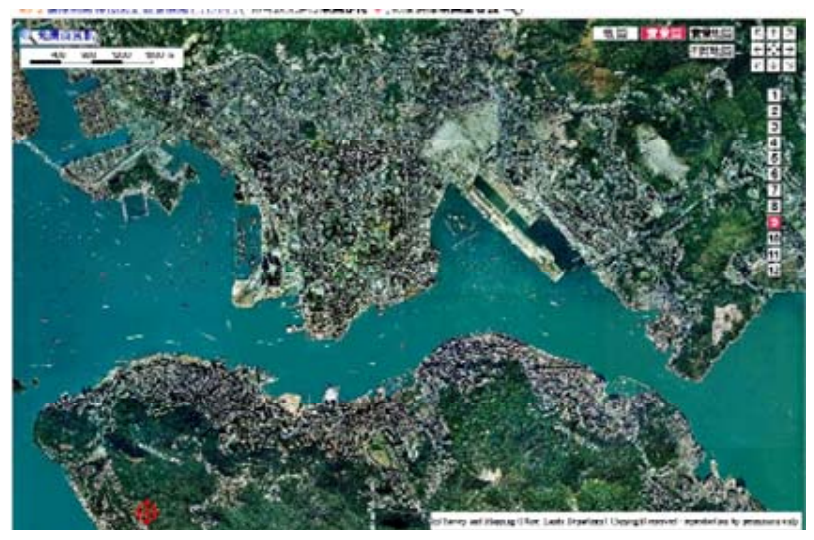

Figure 1.

Compact city of Hong Kong.

The development of high-rise apartments can be traced back to the start of the early 1970s with the evolution of the Pre-War 2-storey shop-houses to the Post-War 7-stories shop-houses ${ }^{1}$, which became even higher when elevators were introduced in the new generation of residences, which allowed them to reach the unlimited height. This happened fast especially when the then new building regulations favored a high floor-to-area ratio, promoting both mixed use and dense development ${ }^{2}$. With an incessant housing demand due to the influx of immigrants and economic growth, the 1980s and 1990s saw the proliferation of thirties to forty stories tall residential skyscrapers.

For many, it is amazing to find that almost up to 90 percent of the 7 million residents live in high-rise apartment buildings in Hong Kong. Based on the official data of 3 persons per family, then there are as many as 2.3 million homes in a tiny built-up area of less than 300 square kilometers. The overall result is a shocking scene for many first-time visitors: chopstick-like buildings standing hand in hand, forging a matrix of concrete forest.

\section{Hierarchical Production of Privacy}

In the highly compact and highly fragmented city of Hong Kong, it is less wonder that social differences are hardly reflected in a horizontal coordinate system at the scale of administrative district or Town Planning Unit (Forrest, Grange, \& Yip, 2004). Alternatively, if we look at the levels of gating in Hong Kong, in other words, the magnificent of the buffer between public and private lives through gating, we may identify a hierarchy of the production of privacy, which marks social differences. The following part of this paper attempts to probe into different tiers in the hierarchical production of privacy, a preliminary study at this stage suggests roughly three tiers.

The first tier goes to zones where the top class concentrates. In the compact city of Hong Kong, these areas are, however, low-rise development zones mainly for enterprisers, with the natural topology making them relatively isolated and forming a geographically distinguished identity. The peak is one wellknown example, aside from several other traditional residential

\footnotetext{
${ }^{1}$ The shop-house is a common sight throughout the history of the Southeast Asia Colonial cities. Typically, the ground floor is for commercial activity while the owner occupies the first floor for convenience sake.

${ }^{2}$ The 1970 Building Ordinance was introduced to permit the design and construction of tall buildings either as single commercial or residence use, or mixed commercial/residential use known as "composite” development.
}

clusters of upper class, such as the Kowloon Tong, and the waterfront at the south of Hong Kong Island, etc.

Following this top tier are the high end and walled residential neighborhoods for the affluent. Developments at the second tier fit better into the image of gated community as it is usually coined in the West, that is, a number of residential buildings that are clustered, together with recreational facilities and amenities constructed for and appreciated by residents only, and walled to form a gated entity, demarcating the insider and the outsider geographically. Although these walled precincts are also developed in a high-density and high-rise pattern, the boundary of the neighborhood server as a visible and strong buffer to separate private life from the busy streets. Usually, such estates are also clustered together, making a given area the reputation of middle class zone.

Next level down is the category we call a vertical gating model, which is an artificial invention of buffer between public and private life through gating at the vertical dimension. This is probably the dominating category that includes the largest number of residential developments, and the category that represents the most common typology of residential development in Hong Kong. Such a HK-style gating reveals an active endeavor to deal with various constraints.

\section{Tier One}

As much of Hong Kong's terrain is hilly and mountainous with steep slopes, early agglomeration of human settlements in Hong Kong was confined to the narrow strip along the Victoria Harbor. At that time, the Chinese settlement was located at the Tai Ping Shan area, now known as the Sheung Wan area; while the British settlement was located at today's Central and Mid-levels. Residential differentiation at the time was mainly characterized by ethical segregation (Bremner \& Lung, 2003). Along with the surge of population, the zone of Chinese community became more and more and crowded, while Chinese people were blamed for their unhygienic habits and lifestyles. In the 1894, a bubonic plague swept through Hong Kong, thus began the 30-year Hong Kong bubonic plague epidemic. The peak of the epidemic was at the first year, afflicted 2679 people, of who 2552 died, at an astonishing mortality rate of $95.3 \%$. The outbreak gave the British government a good reason to legally separate the Chinese and the foreigners, as Sir William Robinson stated clearly in his report to the Marquess of Ripon in 1894 that the cause of the event, he thought, was "the filthy habits of life amongst the 210,000 Chinese who reside here... have rendered Hong Kong liable to the invasion and development of the germ of the bubonic plague (cited by Pryor ,1975)”.

Foreigners, mainly British families, moved upper and upper to the Victoria Peak, where lavish greenery, fresh air and proximity to nature cherished. In 1904, a law was promulgated that the Chinese were forbidden to live on the Peak, which was demarcated as residence for people who led a more civilized life. After scores of years' struggle and negotiation, Chinese elites eventually saw the abolishment of the policy in 1947 (Bremner \& Lung, 2003). The famous tycoon Sir Robert Ho Tung was the first Chinese who moved to the residence on the Peak. Still, it should be kept in mind that the top market price of this area made it only affordable by celebrities and the very wealthy. The ethnical feature of the Peak decayed since then, but the status as the superior residence sustains and even becomes more enhanced across historical episodes. 
To date, a lot of developments on the Peak were constructed in the 70s and 80s, when Hong Kong's economy boomed. Except some detached houses for self-uses, many of the residential buildings were developed by developers for leasing. In fact, it is not troublesome to produce the distinctiveness of this zone, its history, its habitants and its location already gives the area prestige.

The geographic advantage of the peak is obvious. Looking down to the densely populated foot of the Victoria Mountain, the Peak enjoys its sight view of the vibrant city and the Victoria Habour, but also appreciates the quite, natural and isolated setting. The steep slope of the Victoria Mountain alone is already able to delineate worries of uphill sprawl through massive developments. The geological feature of the mountain ridge itself, at the same time, also leads to a relatively scattered distribution of buildings within the boundary of the Peak. Here is a place featured by low-density and low-rise development.

The elevation differences between the peak and the CBD (Central) can be a problem at that time when sedan chair was the main vehicle for transport. As early as 1881, Alexander F. Smith, owner of a hotel on the Peak, petitioned for the right to introduce a funicular railway to Hong Kong. The government took this seriously and carried out a revolutionary infrastructure project to solve the problem (Ng, 1990; Hui, 2000). After three years' hard work by manpower to haul all equipments and rails uphill without mechanical support, the project of Peak Tram was finally put into use in 1888. Only residents of Victoria Peak were eligible to use this service at the beginning. In return, this service certainly boosted the housing stocks on the Victoria
Peak and the Mid-levels. Naturally the dependence on the tram was later given up by the residents, thanks to the industrialization process which introduced automobile to transportation. Car-based commutes soon became the prime way for its speed, convenience, and more importantly, privatized commuting experience.

In sum, the natural setting of this zone alone already provides the most privatized life in Hong Kong Kong (Figure 2). Still, this does not meant that real estate developers may neglect architectural gating strategies. Walls, gates with door controlled by personal access code, and CCTV system are also taken as necessities. Moreover, much better equipments and more advanced technologies are being deployed in these esteemed estates, together with more densely arranged security guards. The cautious gating here, as argued by the authors, may merely be designed to demonstrate a high quality of concierge service to match the sky-rocketed cost of the residences.

\section{Tier Two}

The category of Tier Two refers to developments that are walled entities, with residential buildings and recreational facilities involved for the exclusive appreciation of the residents only. Like those in Tier One, agglomeration of residential developments in Tier Two is also detectable at the horizontal dimension. Such clusters, beside the walls at the micro level of neighborhood, offer a sense of belonging and taken up the role of buffer between "us" within this cluster and "them" outside it.

Mid-level is a typical representative of such clusters. This zone is mainly occupied by the upper-middle class, a high pro-
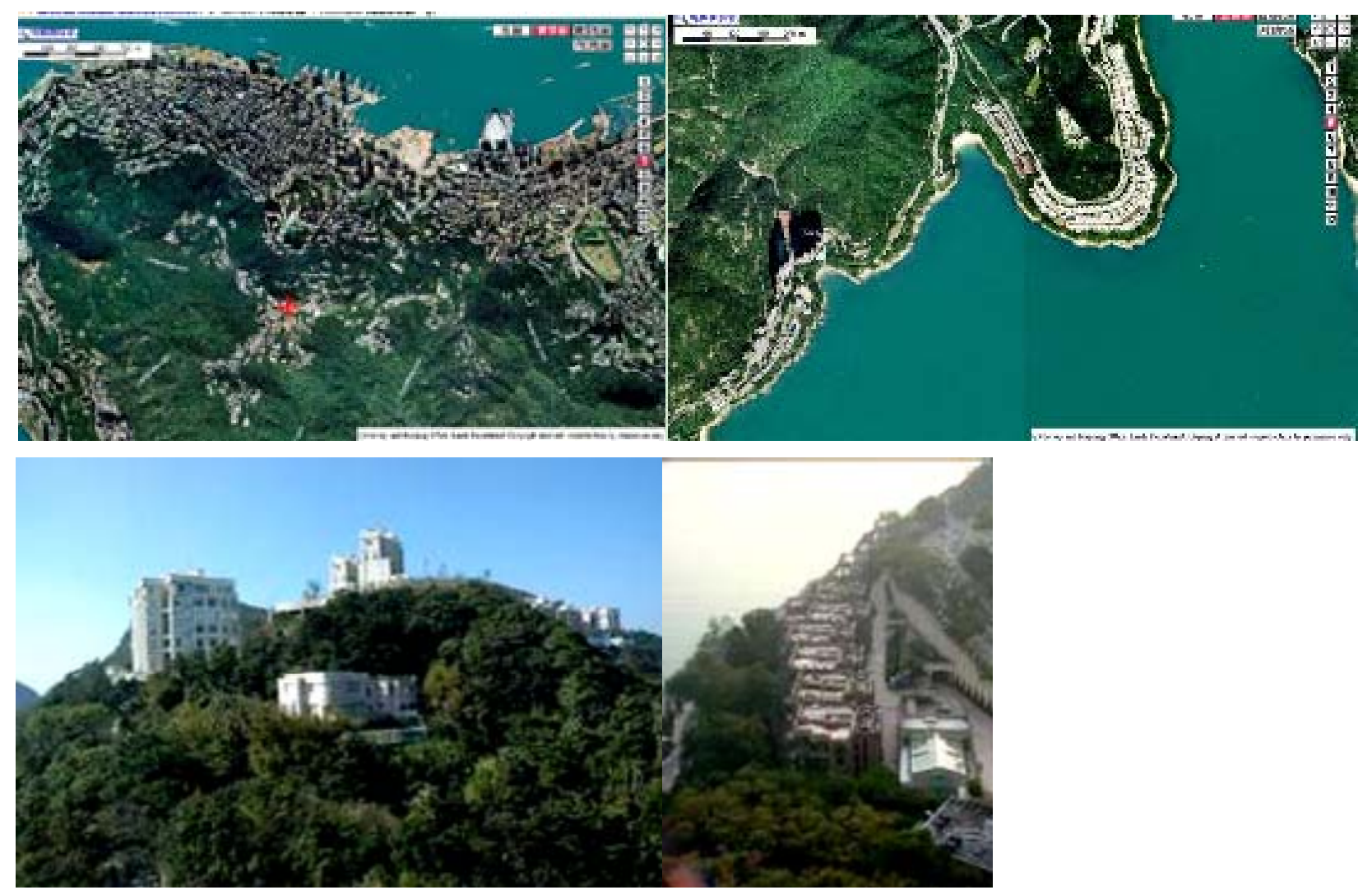

Figure 2.

Gated communities in Tier One are usually with geographically distinctive identities. 
portion of whom are foreign expatriates, singles or couples, well educated, working in the financial industry, the "thinking in English" group as widely referred to in the city. The high density of high end estates makes the zone of Mid-level more like a brand representing a middle class life.

As indicated by its name, the Mid-level is located along the waist of the Victoria Mountain, between the very upper end of the Peak and the CBD area of Central, Sheung Wan and Western District. Also like the $1^{\text {st }}$ tier of upper class society, this tier also enjoys its special geographic and topographic location. Located on the slope of Victoria Mountain, the zone is less accessible by the ordinary people, particularly those who rely on public transit system. Aside from that, the sloping site allows for unobstructed views and greenery with a less urbanized context adding to the value and image of these upper middle class communities.

Again, this zone also faces a difficulty in vertical commuting terms. As a resolution, the world's longest outdoor covered escalator system recorded in Guinness World Records was proposed in 1987 and then opened in 1993, costing HK\$245 million for construction and a HK\$0.95 million for annual maintenance (Lhato November 06, 1996). The "Central-Midlevels” escalators are 800 meters long, climbing up 135 meters from the CBD (Central) to the Mid-level. Everyday from 6 am to $10 \mathrm{am}$, these escalators run downhill to send residents living at Mid-level to their work place- -the Central. The same system will reverse its direction and run uphill after 10:30 am, offering a ride back home for those Mid-level dwellers after work (see Figure 3).

These entities have a homogeneous socio-economic status across those living within the gated entity and regulated by private associations, estates managements for a monthly fee with facilities such as swimming pools, gym, and club house with its inhabitants leading a "club" like lifestyle. The walled podiums and restricted access protects privacy and public property from the outsiders creating a certain exclusivity and identity that is desired by the upper middle class. The implications of high density and mixing of land uses such as over crowding — lack of privacy - fear of crime are kept at bay by the elimination of public facilities such as shopping malls, cinemas and the major public transit mode such as the MTR that draws in mass population which can be an infringement to the privacy of gated communities.

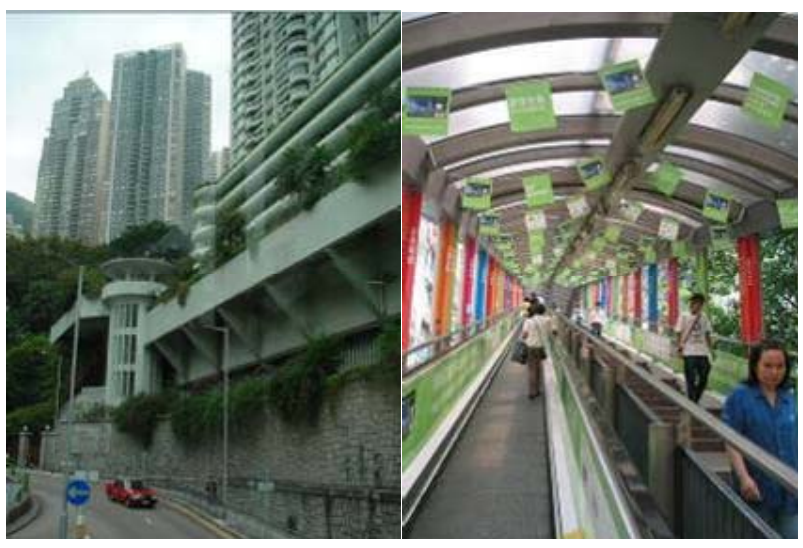

Figure 3.

Gated communities in Tier two fit in the usual definition coined in the West.

\section{Tier Three}

Model at the third tier is a unique product that is "Made-inHong Kong”. It is to be noted that the average housing price for each tier also goes down in the hierarchy. When it comes down to the third tier, housing stock alone is not seen as enough to meet the expectation for profit return. The potential of land for capital accumulation is explored through many perspectives. Increased plot ratio and intensified exploitation of land became the two main approaches, both of which led to the invention of composite development, where private residential towers are built on top of commercial buildings that are open to the public. In order to explore the process, it is necessary to address the series of revisions made to policy on development control in Hong Kong.

Land development control in Hong Kong is exercised under a series of legislative measures and administrative incentives. Planning guidelines, land lease conditions and building controls comprise the main thrust of these measures (Tang \& Tang 1999). The Town Planning Ordinance (Chapter 131 of the Laws of Hong Kong) and the Hong Kong Planning Standards and Guidelines (PDHK 2002) define permissible uses and urban forms in general. The Town Planning Board ensures compliance of development plans with government intentions. Under the Building Ordinance (Chapter 123 of the Laws of Hong Kong), the Buildings Department vets all private building plans.

Given the scarcity of flat land and the incessant growth of population in Hong Kong, the values of development land are high by world standards. Such values, for property valuation or appraisal purpose, are calculated by reference to the "plot ratio" or the ratio between the permitted total floor areas (gross floor area) to the gross site area of a site. Plot ratio for a give land use has been defined clearly in government document. For instance, the legal maxima for typical pure residential and pure commercial buildings are 10 and 15 respectively according to the building ordinance.

However, this does not mean that there is no space for negotiation. The property market was soon dominated by a cartel of profit-seeking real estate developers who tried every means within the bound of the laws to acquire build-able land in the private as well as the public market. The gain to a developer, as revealed by Lai and Ho (2003), “upon... the right to develop a [land] use with a higher value (e.g., commercial instead of residential) and/or a higher plot ratio". The development of Hong Kong to its compactness as we see today is a reflection of the incessant negotiations and compromises between the developers and the government, mainly on maximization of plot ratio and upgrading from lower valued land use to higher valued land use.

\section{1) Maximization of floor space and plot ratio}

In the period of the late 1960s and early 1970s, the government faced the serious situation where the shortage of land for residential supply was met with surge in housing demand because of the surplus of immigrants. To overcome this immediate problem, the government devised a solution, allowing the developers to build outside the boundary of their lot by paying a "rent" for the use of the adjacent space immediately outside the boundary that was defined by the pavement or side-walk. One could still see this unique building typology today in many of the old urban centers such as Nathan Road in Tsim Sha Tsui.

Into the 1970s, the building regulation for sun shadow that prevailed in almost every country to prevent the built over of 
the urban center against the ingress of sunlight onto the streets was abandoned in Hong Kong. This unprecedented act allowed buildings to be built taller and taller without having to step back as building height increased. In this way, another barrier was cleared and the door to vertical development was open widely.

The 1980s saw the affluent status of Hong Kong merged as the top 40 world city by GDP. Powerful real estate developers pressurized the government to devise methods for intensification of land. "Bay window" is devised at this time to enlarge the floor area. A reference was made to the English Edwardian or Victorian houses that have a feature of "projected window" beyond the building facade. The government was persuaded to make relaxation of the building regulations to permit the "bay window" as a bonus rewarded to developers. It is a bonus because the bay window is a saleable area whilst the developers do not have to pay for extra compensation to the government.

Later on, additional floor area is taken as an ever-efficient incentive when the government's call for the developers' responsibility to society. The response to a growing concern in sustainability is a good example. In the mid 1990s, to trigger developers' interest in adding green features to building design, the government, again, modified the building regulations. According to the revised regulation, spaces that may contribute to sustainable performance of the building are exempted from counting of "floor area", such as balcony, extended lobby space and "sky garden", etc.

2) Land use with a higher value

The new leases can alter land uses as well. If the proposed use or plot ratio was not in line with what the old lease allowed, developers can pay the government for a "lease modification" that permits the change in use and/or relaxation in plot ratio (Lai \& Ho, 2003). Changes in land use and development densities are approved after examining relevant public transport constraints. Further, the Planning Department can allow additional uses over those permitted on a case-by-case basis (PDHK, 2002).

In the 1970s, the zoning "Other Use (composite redevelopment area)" was first introduced to cover entire street blocks or precincts in the old urban areas. The category was later renamed "Comprehensive Development Area" (CDA), with the intention to encourage comprehensive development rather than piecemeal fashion. Green light was given to the new invention called "composite development" where commercial and residential uses are erected on the same land parcel in a vertically overlapping form. The Planning Guidelines for the New Towns have permitted non-domestic uses in addition to a domestic plot ratio of 5 . The non-domestic plot ratio was limited by a composite formula (PDHK, 2002). In 1994, a two tier plot ratio system was introduced for Kowloon and New Kowloon areas to improve the provision of multiple services through composite development (Tang \& Tang, 1999). This system permitted a maximum gross plot ratio of 7.5 for residential developments for plot sizes of over 400 sq. meters, with the residential share being 6 , and the non-domestic space taking up the balance 1.5 (PDHK, 2002). Further, the HKPSG allows additional nondomestic plot ratio while reducing the domestic plot ratio correspondingly based on the composite formula (PDHK, 2002). The two tier plot ratio system allocates larger proportion of the total gross floor area to non-domestic land use, or frequently, commercial use, which is of higher value than residential use. Taking an example of the Kowloon Station development, the project has achieved a residential plot ratio of approximately
4.2 and an increased non-domestic ratio of about 3.5, for a gross value of 7.7. In practices, many of the activities in these zones are market generated rather than planning requirements.

\section{3) The Multiple Intensive Land Use (MILU) model}

The first application of such composite developmental model by way of modularized housing for Hong Kong is the Mei Fu Shan Chuen, a private investment, which began in 1969, and more or less finished in 1970, followed by subsequent stages of expansion over time until 1989 (Figure 4). Mei Fu today has 117 towers of 15 stories tall apartment buildings built on four adjoining sites making a self-contained town for its 46,245 mid-income group of residents or 13,068 households (Lau \& Wang, 2002).

The Mei Fu is an exaggerated version of the shop on ground and residence on floors above, made possible by a collage of land use functions on the ground and the upper floors such as bus terminus, food markets, gardens, sports ground, cinema and shops. The Mei Fu is an evolution of the Corbusier model for future city became a model for the rest of the developments in the city in subsequent years.

The success of the Mei Fu experiment is built upon an acceptance of high rise living by the people that led the developers to see a lucrative prospect. It was recognized to be a self-sufficient and mixed land use model, and was taken as a ground-breaking model in urban design by architects, planners and officials beyond the Corbusier model. Projects that replicate the Mei Fu Model or making gradual advancement followed and flourished over the next decades. For plot of lands sites which are restrictive in sizes, designers have no hesitation but to adopt a vertical approach. What evolved are towers of multi-stories residential apartments on top of a podium that houses all kinds of ancillary facilities.

\section{4) Producing privacy at the vertical dimension}

The podium model became a dominating approach from the 1980s to present. Typically, such model stacks residential towers that house private life on a podium that house non-domestic facilities. Following that, connections of adjacent podiums through weather proof foot bridges is another important component to enhance accessibility of the development. This is an idea borrowed from the commercial centers (especially in the Hong Kong Central, Wanchai and Tsim Sha Tsui areas) where networks of pedestrian walkways are crisscrossing in and out of buildings or over roads and pavements. Such high accessibility

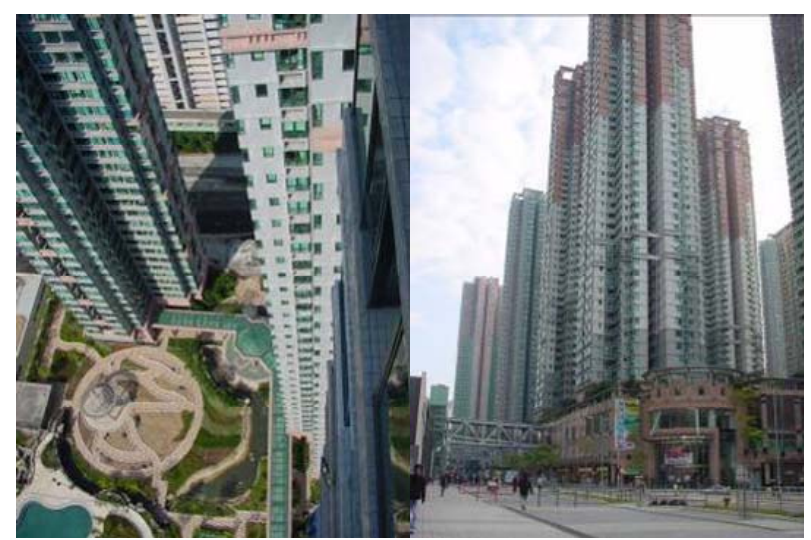

Figure 4.

In Tier Three, gating at the vertical dimension invents another dimension to measure social differences. 
has proved to be able to ensure the popularity of the developments, both domestic and non-domestic, in the housing market. In many cases, the overlapping and mixing of functions make it difficult for one to determine whether the building should be classified as commercial or residential.

The pursuit of higher plot ratio and more intensified exploration of land, not only maximize the total floor area that are put into the housing market, but also enlarge the proportion of commercial floor area that asks for higher rent than pure residential space. All these indicate a higher profit return, on the one hand. However, on the other hand, such a model that pushes private and public lives together to an extreme of closeness leaves privacy to danger.

Privacy does matter in Hong Kong. In her study of socialist work unit compound in Chinese cities, Huang (2006) identified the traditional "collectivist culture" and "political control" as major contributors of gating in Chinese society. Accordingly, the Chinese may have a higher tolerance of lower privacy. But with the modernization and high densities in Hong Kong, social implications such as lack of privacy, over crowding and lack of control over public and private space, may cause different trends in the micro culture.

In Hong Kong, space proximity or the smaller distance between buildings is taken as a tolerable rather than a desirable spatial attribute (Lau \& Coorrey, 2007). On a slightly varied context, the discussion here may be shifted to another facet of Hong Kong's transient way of life, where everything is space-constraint and congested as to constitute a phobia, it became an irresistible need for many families to "borrow" space whenever one feels the need (Lau \& Wang, 2002). Here "borrowed" space refers to the extension of social space by such means as restaurants, coffee shops or even street eating. In Hong Kong, where most apartment homes have a relatively small home, many families prefer to entertain their guests or friends out of homes but commercial places, making these places extended homes (Lau \& Wang, 2002). In this way, the "borrowed" space serve as an extension of private life, restaurant replaces the dining room and the Karaoke Lounge replaces the living room at home. When part of private life is publicized, the remaining parts of private life need more than a cautious protection (See Figure 5).

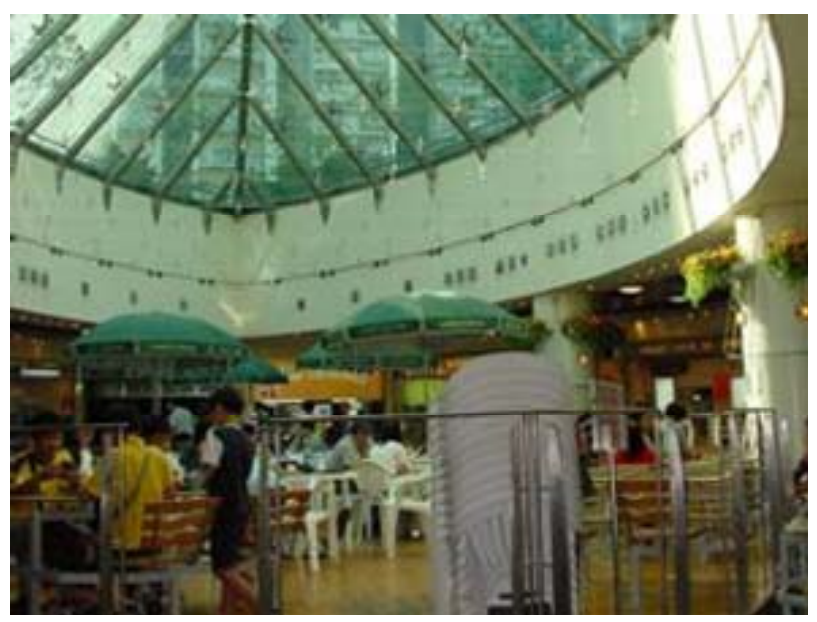

Figure 5.

Composite development packs private and public life to an extreme of closeness.
A clear demarcation of public to private spaces, over use, infringement to privacy of residents, crime, fear and vandalism needs to be controlled to maintain the attractiveness of housing stocks in these composite developments. Under the deck, i.e., roof of the podium are car park, or probably a major public bus interchange, shopping malls, food markets, supermarket, banks and post office; in one sentence, a busy public space. Often above the deck is a landscaped park, playground, swimming pool, club house, tennis courts, and jogging path, all for the exclusive use by residents living in the towers above (Lau \& Wang, 2002). Between the public and private lives, the role of physical gating can not be more important.

A lot of architectural means are used to ensure the impression of protected private life and secured separation for residents. Frequently, different names are given to the part above the deck and the part below the deck. For instance, the residential part of a development near the campus of the University of Hong Kong is entitled “The Belcher's”, whilst the commercial part is named "Westwood's". Accesses are designed at different levels to separate the flux of different population segments. Sign boards for the two parts are located at different places. Visual and aesthetical variations are also important. Different architectural languages, like materials, scales, and even architectural styles for some cases, are used to ensure the insiders and the outsiders have clear impression of the social group they belong to, where they should go and what they should conduct. Residents normally enter the complex through secured lobbies, wherein elevators going directly to the residential towers operate only after identities of the residents have been screened. Another series of elevators in the podium are designed to serve the public, frequently in the form of escalators. Residents' attachment to the community, if any, refers to the place above the deck only, although all the built structures are in fact the same development by the same developer.

\section{Discussion and Concluding Remarks}

In the discussion on gated community and its acceptance in Hong Kong, it is necessary to recall those comments by a psychologist whom the authors interviewed back in 2002 when researching on high-rise living in mega-cities. He said, the advantage of living in a monotonously looking high-rise building is the ability for the resident to "disappear completely and unnoticeably" into the building and "be secluded from the rest of the community at once"; in this way, one achieves "privacy" by being lost in an identity-less setting. This conversation reminded the authors of the simile with a person attached to a mobile phone number, once the phone is switched on, the person is connected with the rest of the world. Once it is switched off, the person disappears immediately without a trace from the world. In a metaphorical sense, living in a high-rise building gives an individual person protection against intrusion, and privacy in the same way as the mobile phone.

As Forrest, Grange and Yip reveal that, social differences in Hong Kong are not reflected in a horizontal coordinate system. In the compact city of Hong Kong, space distance is argued to be a rare urban resource. The competition for buffer between public and private leads to a hierarchy of production of privacy.

After hundred years of negotiations between the developers and the government, the resulting model of composite development packs private life and public life to an extreme of closeness. For those at the top of social strata, privacy is gained 
through natural settings or physical distance. For the mass populace, the value of gating at the vertical level is then recognized by the developers, who purposely exploit architectural gating to produce a feeling of privacy. Here gating gives residents another way to feel the distinguished "us" from "them". Gating becomes a psychological interpretation of physical spatial distance, which is a rare urban resource in the densely populated Hong Kong. When value addition through plot ratio/value of land use threats the privacy, gating is employed to produce the image of private life, emphasizing the separation of the public and the private and through which, privacy is also valorized.

Social differences may be detected at the vertical dimension, as residents within the same tower tend to be homogeneous whilst differences of residents in two towers can be large. Gating at the vertical dimension invents a third dimension on spatiality, that is, secondary characteristics to mark the social differences besides the horizontal geographic one.

When the compact developing mode of Hong Kong is proudly advocated as a way towards sustainability and followed by other cities, it is ironic to see gating becomes one imperative contributor towards the tolerance and acceptance of Hong Kong people to lead such a compact life.

\section{REFERENCES}

Alexander, E. R., Reed, K. D., \& Murphy, P. (1988). Density measures and their relation to urban form. Milwaukee: Center for Architecture and Urban Planning, University of Wisconsin.

Atkinson, R., \& Sarah, B. (2005). Introduction: International perspectives on the new enclavism and the rise of gated community. Housing Studies, 20, 177-186.

doi:10.1080/0267303042000331718

Atkinson, R., Sarah, B., Flint, J., \& Lister, D. (2004). Gated communities in England London: Office of the Deputy Prime Minister.

Bourdieu, P. (1984). Distinction: A Social Critique of the Judgment of Taste. Cambridge: Harvard University Press.

Bremner, G. A., \& Lung, D. P. Y. (2003). Spaces pf exclusion: The significance of cultural identity in the formation of European residential districts in British Hong Kong, 1877-1904. Environment and Planning D: Society and Space, 21, 223-252. doi:10.1068/d310

Chan, Y. K. (1999). Privacy: Does it concern the people? In S.-K. Lau (Ed.), Indicators of Social Development: Hong Kong 1997. Hong Kong: The Chinese University of Hong Kong.

Forrest, R., La Grange, A., \& Yip, N.-M. (2004). Hong Kong as a global city? Social distance and spatial differentiation. Urban Studies, 41, 207-227. doi:10.1080/0042098032000155759
Huang, Y. Q. (2006). Collectivism, political control, and gating in Chinese cities. Urban Geography, 27, 507-525. doi:10.2747/0272-3638.27.6.507

Hui, C.-S. E. (2000). Peak tram sation: Extension, architecture. Hong Kong: University of Hong Kong.

Knapp, R. G. (1999). China's Old Dwellings. Honolulu, HI: University of Hawaii Press.

Knapp, R. G. (2000). China's Walled Cities. New York: Oxford University Press.

Lai, L. W. C., \& Winky, K. O. H. (2003). Modeling development control of residential development: A probit analysis of rent seeking and policy autonomy in town planning in Hong Kong. In F. H. Columbus (Ed.), Asian economics and political issues. New York: Nova Publisher.

Lau, S. S. Y., \& Wang, X. (2002). Pursuing new urban living environment in the new millennium: Projecting the future of high-rise and high density living in Hong Kong. In Generative Art International Conference 2002. Milan.

Lau, S. S. Y., \& Coorrey, S. B. (2007). Hong Kong: Milu and how it is perceived. In H. A. Haccou, T. Deelstra, A. Jain, V. Parmer, K. Krosnicka, \& R. D. Waard, (Eds.), Milunet: Multifunctional intensive landuse-Principles, practices, projects, policies-Towards sustainable area development. Neitherlands: Harbiforum Foundation.

Lhato, Y. (1996). Escalator “a costly white elephant”. The Standard.

Li, L. H., \& Amy, S. (2001). Privatising management services in subsidised housing in Hong Kong. Property Management, 19, 37-49.

Manzi, T., \& Bill, S.-B. (2005). Gated communities as club goods: Segregation or social cohension? Housing Studies, 20, 345-359. doi:10.1080/0267303042000331817

Mitchell, D. (1995). The end of public space? Annals of the Association of American Geographers, 85, 108-133.

Mitchell, R. E. (1971). Some social effects of high density housing. American Sociological Review, 36, 18-29. doi:10.2307/2093503

Ng, R. F. (1990). Narrative of a city: Peak tram station, Victoria Peak, Hong Kong, Graduate School of Design, Harvard University.

Planning Department of Hong Kong (PDHK) (2002). Hong Kong planning standards and guidelines Hong Kong planning department of Hong Kong.

Pryor, E. G. (1975). The great plague of Hong Kong. Journal of the Hong Kong Branch of the Royal Asiatic Society, 15, 61-70.

Tang, B., \& Tang, R. M. H. (1999). Development control, planning incentive and urban redevelopment: Evaluation of a two-tier plot ratio system in Hong Kong. Land Use Policy, 16, 33-43. doi:10.1016/S0264-8377(98)00035-0

Webster, C. (2001). Gated cities of tomorrow. Town Planning Review, $72,149-169$

Webster, C., Glasze, G., \& Frantz, K. (2002). The global spread of gated communities. Environment and Planning B, 29, 315-320. doi:10.1068/b12926 